\title{
СРАВНИТЕЛЬНАЯ ХАРАКТЕРИСТИКА ОРГАНИЧЕСКОГО ВЕЩЕСТВА ДОКЕМБРИИСКИХ СЛАНЦЕВ ЭСТОНСКОЙ ССР И ИРКУТСКОЙ ОБЛАСТИ
}

\author{
Представлена О. Эйзеном
}

В последнее время значительно возрос интерес к органическому веществу (OB) докембрийских отложений - в основном в связи с проблемой происхождения жизни. Обзор имеющихся сведений о составе дофанерозойского ОВ приведен в монографии [ $\left.{ }^{1}\right]$. В настоящей работе исследовался химический состав ОВ двух докембрийских пород - алевролито-глинистого сланца Эстонской ССР (венд) и углистого аргиллита Иркутской области (рифей).

Образец породы котлинской свиты был отобран в Северной Эстонии (район Виру-Нигула) с глубины 162,5-172,0 м; ОВ сланца характеризуется как сапропелевое $\left[{ }^{2}\right]$. Проба углистого аргиллита отобрана из хомолхинской (валюхтинской) свиты патомской серии в районе Сухого Лога Иркутской области *; ОВ сланца относится к графитоидному типу.

Обработанная $10 \%$-ной соляной кислотой порода экстрагировалась при комнатной температуре последовательно смесью бензол-метанол (3:1) и диэтиловым эфиром. Суммарные битумоиды освобождались от элементной серы и неорганических солей по методике [ $\left.{ }^{3}\right]$, кислоты выделялись кипячением с 0,5 н. спиртовым раствором гидроокиси калия. Часть кислотных соединений не экстрагируется из подкисленного раствора эфиром, поэтому такие высокомолекулярные («гуминовые») кислоты выделялись фильтрованием. Нейтральная часть битумоидов была разделена на группы соединений методом тонкослойной хроматографии по методике $\left[{ }^{4}\right]$ на силикагеле Л, элюент - - -гексан. Групповые компоненты битумоидов анализировались газохроматографически на аппарате Хром-4 с применением колонок различной полярности. Для выделения аминокислот проводился гидролиз сланцев 6 н. соляной кислотой на кипящей водяной бане в течение 24 , анализ аминокислотного состава гидролизатов осуществлялся на автоматическом анализаторе типа 6020 (Чехословакия). ** Часть дебитуминированного сланца обогащалась обработкой концентрированными соляной и плавиковой кислотами $\left[{ }^{5}\right]$. Исходный и обогащенный сланцы подвергались термической деструкции в лабораторной реторте при стандартном режиме нагрева (ГОСТ 3168-66), состав смол и газов полукоксования исследо-

\footnotetext{
* Образец аргиллита был предоставлен нам для исследования Д. И. Дроботом (Вост.-Сиб. н.-и. ин-т геологии, геохимии и минер. сырья).

** Анализ проведен М. Куузик под руководством Л, Наппа,
} 
Характеристика исходных лобразцов и продуктов

их кислотного обогащения, вес. \%

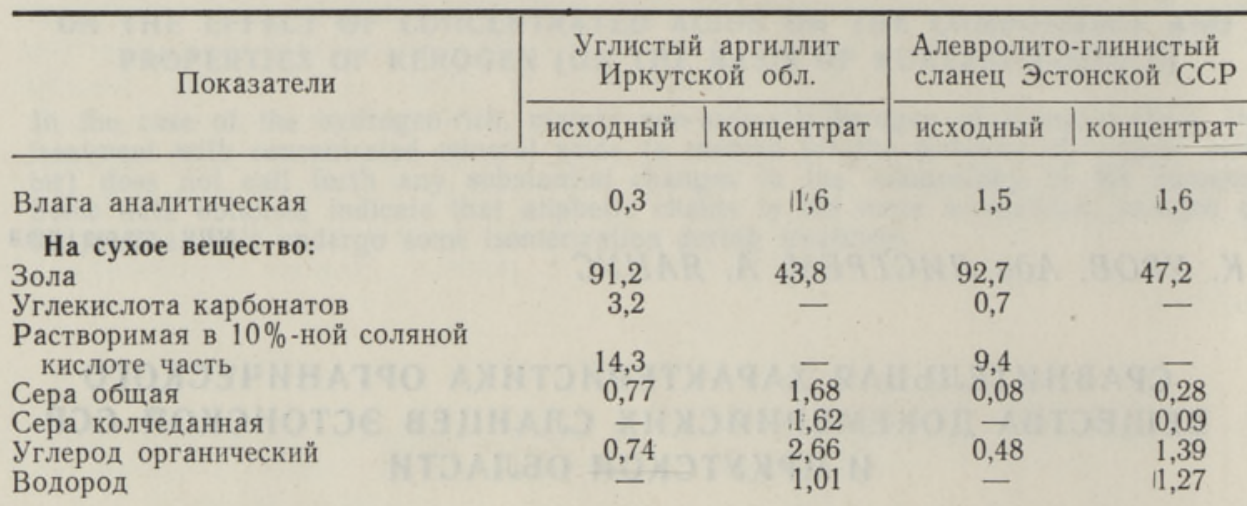

Характеристика битумоидов, вес. \%

\begin{tabular}{c|c|c}
\hline Показатели & $\begin{array}{c}\text { Углистый } \\
\text { аргиллит }\end{array}$ & $\begin{array}{c}\text { Алевроли- } \\
\text { то-глини- } \\
\text { стый } \\
\text { сланец }\end{array}$ \\
\hline
\end{tabular}

Выход битумоида на породу

Элементный состав:

$$
\begin{aligned}
& \text { углерод } \\
& \text { водород } \\
& \text { гетероатомы } \\
& (\mathrm{H} / \mathrm{C}) \text { атом. }
\end{aligned}
$$

Битумоидный коэффициент по углероду $\left(\beta_{c}\right)$

Групповой химический состав: неароматические углеводороды ароматические углеводороды нейтральные гетероатомные соединения

кислотные соединения из них эфирорастворимые

$\begin{array}{cc}0,016 & 0,045 \\ 68,1 & 60,0 \\ 9,7 & 7,1 \\ 22,2 & 32,9 \\ 1,71 & 1,42 \\ 1,4 & 4,7 \\ 14 & 9 \\ 3 & 4 \\ 5 & \\ 78 & 23 \\ 51 & 64 \\ & 2\end{array}$

вался газохроматографически. Инфракрасные спектры снимались на аппарате UR-10.

Характеристика исходных и обогащенных сланцев приведена в табл. 1. Содержание ОВ в концентратах кислотного обогащения (выход продукта обработки, соответственно, 33 и $39 \%$ от аргиллита и алевролито-глинистого сланца) было слишком низким для точного определения его количества и элементного состава. Концентраты содержали значительное количество летучих неорганических солей.

Судя по низкому битумоидному коэффициенту, обогащенности экстрактов гетероатомами и гетероатомными соединениями (табл. 2), оба битумоида являются автохтонными $\left[{ }^{6}\right]$. В пользу этого свидетельствует близость их инфракрасных спектров (рис. 1) типовым спектрам сингенетических битумоидов $\left[{ }^{7}\right]$. Однако ни по элементному, ни по групповому составу битумоиды не идентичны. Битумоид аргиллита обладает явными признаками термометаморфизованности (ср. наличие в инфракрасном спектре комплекса полос поглощения, свойственных ароматическим соединениям: $750,840,900,970,1020,1040,1080,1600,1850$ и $\left.3080 \mathrm{~cm}^{-1}\right)$, что совпадает с данными по геологической истории верхне- 


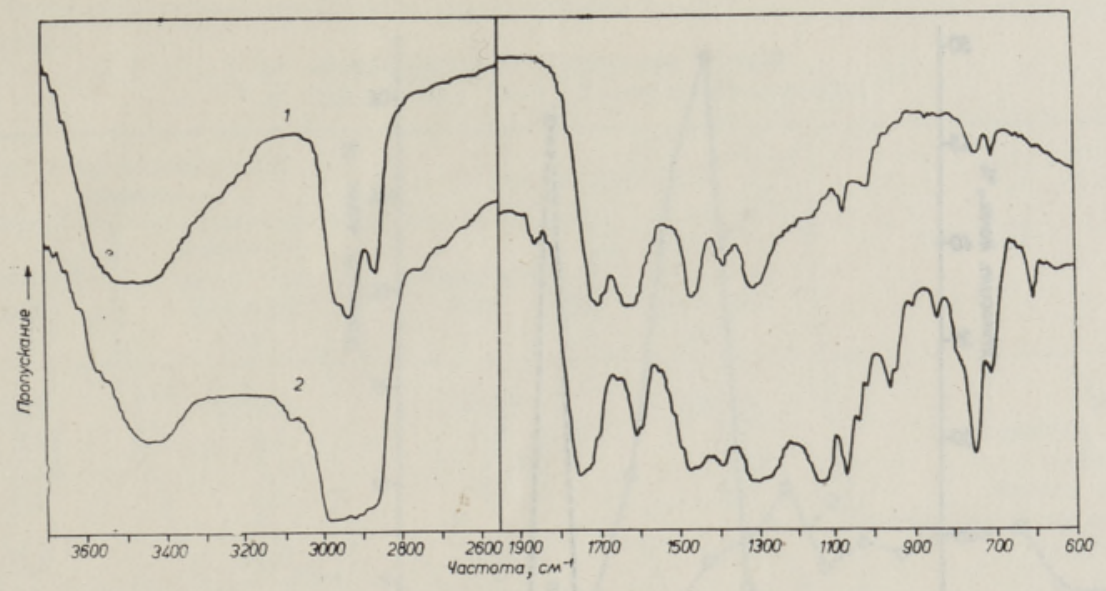

Рис. 1. Инфракрасные спектры битумоидов алевролито-глинистого сланца (1) и углистого аргиллита (2).

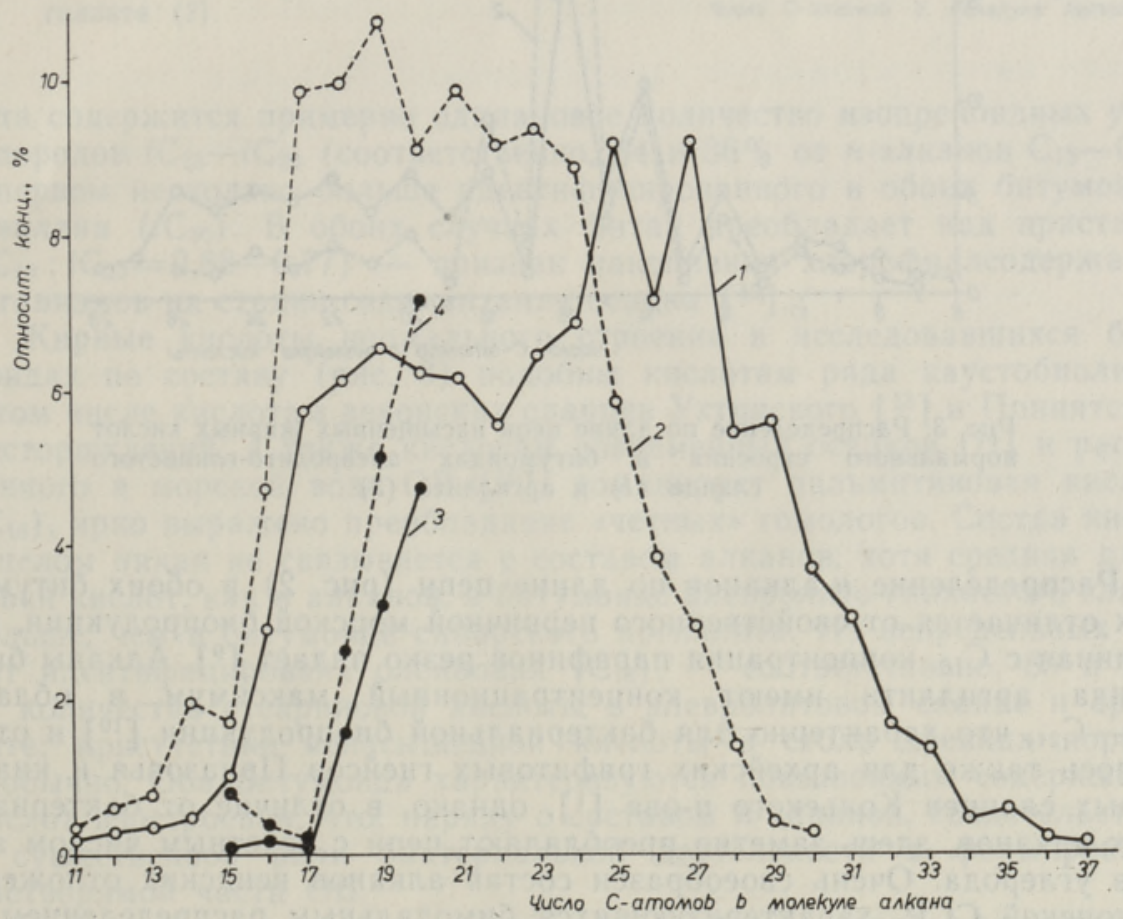

Рис. 2. Распределение по длине цепи $н$-алканов $(1,2)$ и изопреноидных углеводородов $(3,4)$ в битумоидах алевролито-глинистого сланца $(1,3)$ и углистого аргиллита $(2,4)$.

протерозойских отложений Патомского нагорья [8]. При этом основными носителями ароматичности здесь, по-видимому, являются гетероатомные соединения, так как концентрация ароматических углеводородов низкая. Битумоиды содержат много гидроксильных и карбонильных групп (рис. 1), содержание кислотных соединений, как обычно в битумоидах $C$, высокое (табл. 2). 


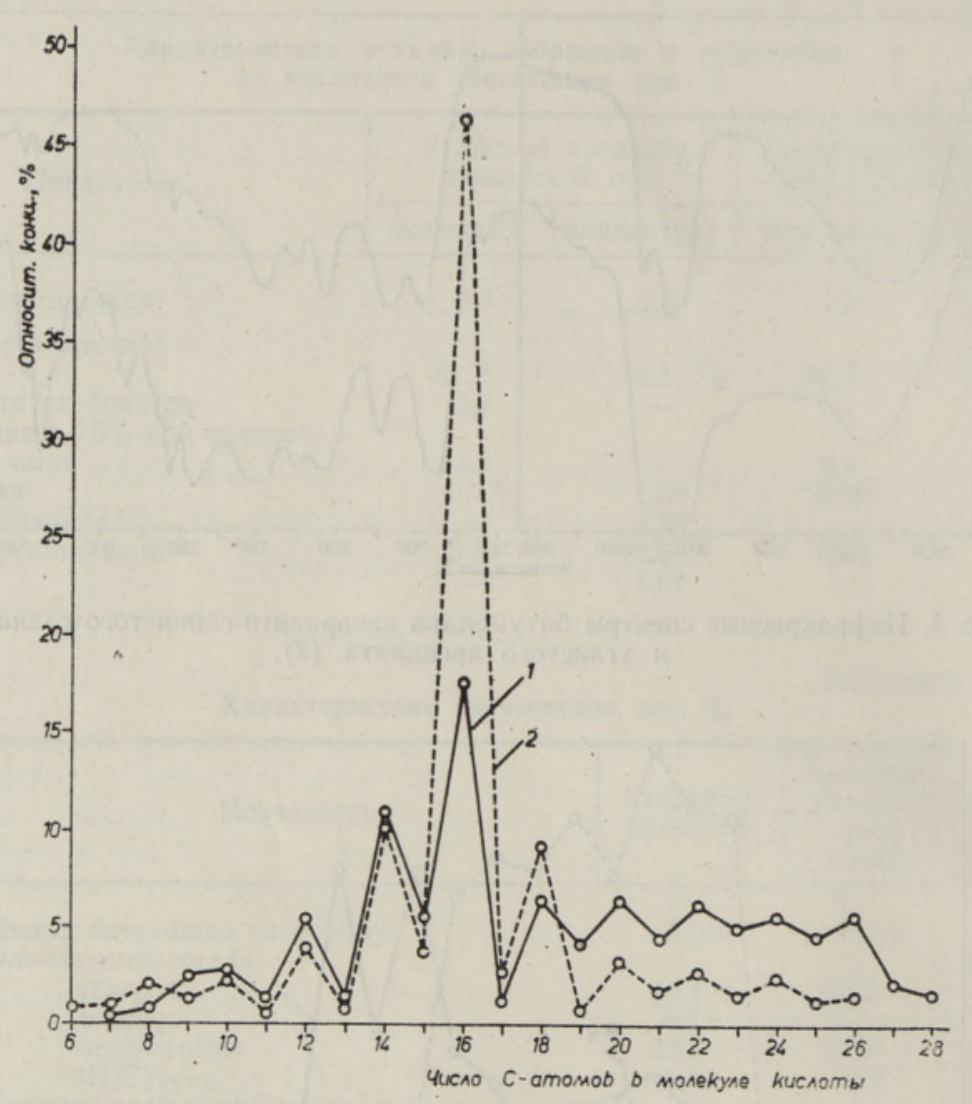

Рис. 3. Распределение по длине цепи насыщенных жирных кислот нормального строения в битумоидах алевролито-глинистого сланца (1) и аргиллита (2).

Распределение $\boldsymbol{H}$-алканов по длине цепи (рис. 2) в обоих битумоидах отличается от свойственного первичной морской биопродукции, где, начиная $\mathrm{c}_{18}$, концентрация парафинов резко падает [ $\left.{ }^{9}\right]$. Алканы битумоида аргиллита имеют концентрационный максимум в области $\mathrm{C}_{17}-\mathrm{C}_{24}$, что характерно для бактериальной биопродукции [ $\left.{ }^{10}\right]$ и отмечалось также для архейских графитовых гнейсов Приазовья и кианитовых сланцев Кольского п-ова [ $\left.{ }^{1}\right]$, однако, в отличие от бактериальных алканов, здесь заметно преобладают цепи с нечетным числом атомов углерода. Очень своеобразен состав алканов вендских отложений Эстонской ССР, характеризующихся бимодальным распределением по длине цепи: наряду с бактериальными парафинами $\left(\mathrm{C}_{17}-\mathrm{C}_{22}\right)$, в них присутствуют алканы $\mathrm{C}_{23}-\mathrm{C}_{30}$ с ярко выраженным преобладанием соединений с нечетным числом атомов углерода в молекуле, что в настоящее время рассматривается как признак терригенного происхождения ископаемого [ $\left.{ }^{11}\right]$. Поскольку в докембрии наземная растительность отсутствовала, то следует допустить, что эти алканы были привнесены из более поздних отложений, чему могла способствовать водоносность смежных с котлинским гдовского $(V g d)$ и ломоносовского $\left(\mathrm{Cm}_{1} \mathrm{~lm}\right)$ горизонтов, или что тогда существовали организмы, способные продуцировать подобные алканы.

В углеводородах битумоидов алевролито-глинистого сланца и аргил- 
Рис. 4. Распределение по длине цепи $н$-алканонов-2 в битумоидах алевролигового сланца (1) и аргиллита (2)

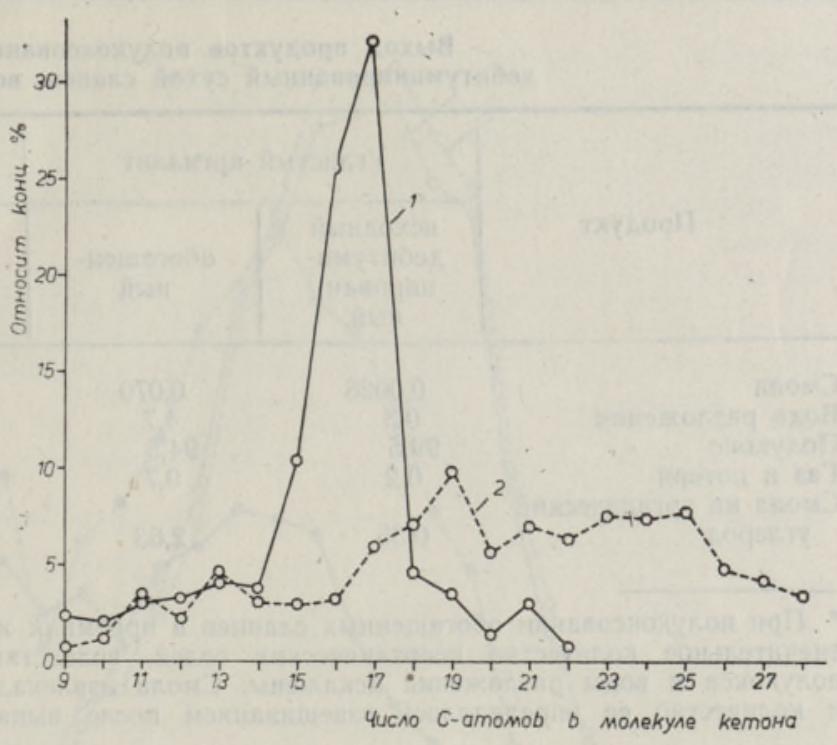

лита содержится примерно одинаковое количество изопреноидных углеводородов $i \mathrm{C}_{15}-i \mathrm{C}_{20}$ (соответственно, 34 и $36 \%$ от $\boldsymbol{H}$-алканов $\mathrm{C}_{15}-\mathrm{C}_{20}$ ), в первом несколько больше идентифицированного в обоих битумоидах сквалана $\left(i \mathrm{C}_{30}\right)$. В обоих случаях фитан преобладает над пристаном $\left(i \mathrm{C}_{19}: i \mathrm{C}_{20}=0,68-0,77\right)$ - признак накопления хлорофиллсодержащих организмов на стадии седиментации осадка [ $\left.{ }^{12}\right]$.

Жирные кислоты нормального строения в исследовавшихся битумоидах по составу (рис. 3) подобны кислотам ряда каустобиолитов, в том числе кислотам девонских сланцев Ухтинского [ $\left.{ }^{1,3}\right]$ и Припятского месторождений, а также кислотам современных осадков [[14] и растворенного в морской воде ОВ $\left[{ }^{15}\right]$ : доминирует пальмитиновая кислота $\left(\mathrm{C}_{16}\right)$, ярко выражено преобладание «четных» гомологов. Состав кислот в целом никак не связывается с составом алканов, хотя средняя длина цепей кислот, как и алканов, в битумоиде алевролито-глинистого сланца больше, чем в битумоиде сибирского аргиллита. Из непредельных кислот идентифицирована олеиновая $\left(\mathrm{C}_{18}\right)$, - соответственно, 85 и $26 \%$ от количества стеариновой кислоты в алевролитовом сланце и аргиллите; присутствие ненасыщенной кислоты в столь древних породах необычно. Оба битумоида характеризуются повышенным содержанием кислот изостроения, что, наряду с составом $H$-алканов, свидетельствует о существенной роли бактериальной деятельности в формировании растворимой части ОВ.

В битумоидах обоих сланцев обнаружены метил-н-алкилкетоны, существенно различающиеся по составу (рис. 4). Если распределение $\mu$-алканонов-2 по длине цепи в аргиллите подобно распределению алканов, то кетоны алевролитового сланца отличаются наличием концентрационного максимума у $\mathrm{C}_{17}$. На хроматограммах нейтральных кислородных соединений битумонда алевролитового сланца обнаруживается гомологический ряд соединений, совпадающий при проверке эталонами с $\boldsymbol{H}$-алканолами-1 $\mathrm{C}_{9}-\mathrm{C}_{16}$, однако содержание спиртов гораздо ниже содержания кетонов. Наши результаты оказались отличными от более ранних $\left[{ }^{16}\right]$ : в битумоиде аргиллита алифатические спирты в заметном количестве обнаружены не были.

Исследовавшиеся сланцы различаются также по количеству и 
Выход продуктов полукоксования на дебитуминированный сухой сланец, вес. \% *

\begin{tabular}{l|c|c|c|c}
\hline \multirow{1}{*}{ Продукт } & \multicolumn{2}{|c|}{ Углистый аргиллит } & \multicolumn{2}{|c}{$\begin{array}{c}\text { Алевролито-глинистый } \\
\text { сланец }\end{array}$} \\
\cline { 2 - 4 } & $\begin{array}{c}\text { исходный } \\
\text { дебитумн- } \\
\text { нирован- } \\
\text { ный }\end{array}$ & $\begin{array}{c}\text { обогащен- } \\
\text { ный }\end{array}$ & $\begin{array}{c}\text { исходный } \\
\text { дебитуми- } \\
\text { нирован- } \\
\text { ный }\end{array}$ & $\begin{array}{c}\text { обогащен- } \\
\text { ный }\end{array}$ \\
\hline Смола & 0,0026 & 0,070 & 0,0028 & 0,137 \\
Вода разложения & 0,3 & 4,7 & 1,0 & 12,6 \\
Полукокс & 99,5 & 94,5 & 97,1 & 0,8 \\
Газ и потери & 0,2 & 0,7 & 1,9 & 9,85 \\
Смола на органический \\
углерод
\end{tabular}

* При полукоксовании обогащенных сланцев в приемник жидких продуктов поступает значительное количество неорганических солей, вследствие чего данные о выходе полукокса и воды разложения искажены. Смола извлекалась из конденсата эфиром, и количество ее определялось взвешиванием после выпаривания экстрагента.

составу высвобождающихся при кислотном гидролизе аминокислот. Если в алевролито-глинистом сланце они находятся только в следах (идентифицированы лизин, валин и лейцин), то в аргиллите их количество уже достаточно для определения состава (в \%: лизин 26,7 ; валин 22,8 ; лейцин 19,4 ; глутаминовая кислота 13,7 ; гистидин 11,4 ; метионин 3,0 ; изолейцин 2,1 ; аргинин, фенилаланин и тирозин - в следах). Указанные аминокислоты свойственны широкому кругу растительных, животных и бактериальных белков.

Данные о выходе продуктов термической деструкции сланцев приведены в табл. 3. Газ полукоксования аргиллита состоит в основном из углекислого газа $(87 \%)$ и содержит относительно много водорода $(11 \%)$. Интересно, что подобный состав имеют также продукты конечного этапа газообразования при катагенезе рифей-вендских отложений Сибири $\left[{ }^{17}\right]$. По нашему мнению, это является результатом реакции ОВ с водой в условиях повышенной температуры при преимущественном рассеивании водорода. Основные компоненты газообразных продуктов разложения алевролито-глинистого сланца $(\%)$ : водород 58 , метан 23 и углекислый газ 13.

Выход смолы полукоксования из исследовавшихся нами сланцев крайне низок, в том числе в расчете на ОВ (табл. 3). Поскольку в случае концентратов выход смолы на кероген возрастает в среднем на порядок, то вероятно, что исходные сланцы по содержанию ОВ близки к состоянию, когда адсорбционная способность минеральной части и смолообразующая способность керогена равны и выделение смолы прекращается.

н-Алканы смол полукоксования необогащенных сланцев практически идентичны по составу и характеризуются наличием концентрационного максимума в области $\mathrm{C}_{23}-\mathrm{C}_{29}$ (рис. 5). Алифатические структуры были найдены также в ОВ древней формации Фиг-Три при пиролизе дебитуминированного керогена $\left[{ }^{18}\right]$. Алифатические цепи в нерастворимой части ОВ сланцев, как и алканы их битумоидов, не свойственны продукции морских автотрофных организмов, их состав близок составу алканов бактериального и терригенного происхождения. Однако это не говорит в пользу аллохтонного характера «терригенных» алканов битумоида алевролитового сланца, более правдоподобно допустить 


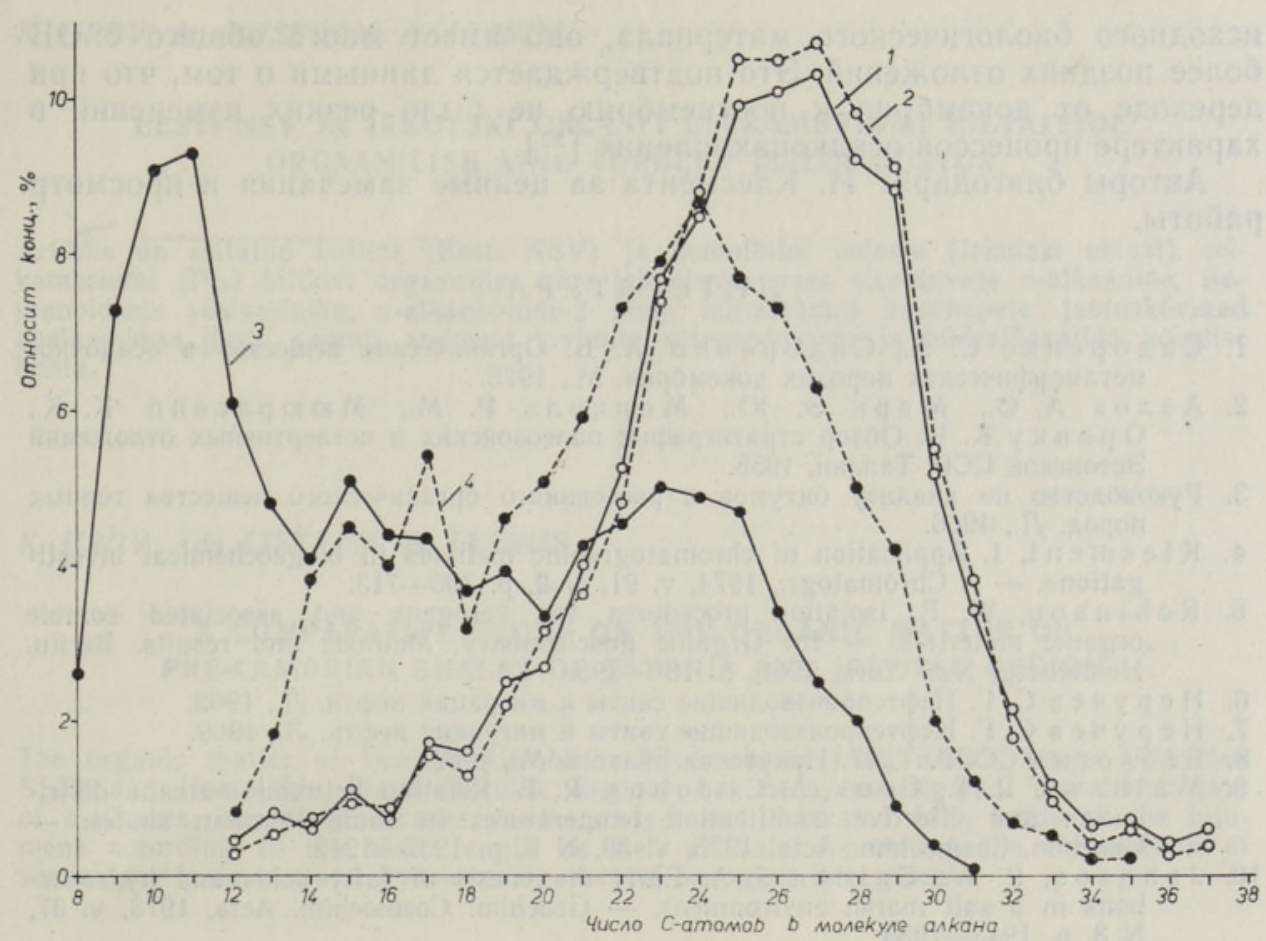

Рис. 5. Распределение по длине цепи $\boldsymbol{H}$-алканов в смолах полукоксования исходного $(1,2)$ и обогащенного кислотами $(3,4)$ алевролито-глинистого сланца $(1,3)$ и углистого аргиллита $(2,4)$.

существование в докембрии организмов, способных продуцировать $H$-алканы $\mathrm{C}_{20}-\mathrm{C}_{35}$ с заметным преобладанием соединений с нечетным числом атомов углерода в молекуле. Если при формировании ОВ аргиллита некоторую роль могли сыграть абиогенный ресинтез под действием метаморфических факторов, частично приводящий к удлинению углеродной цепи $\left[{ }^{19}\right]$, или сепарация углеводородов в результате миграционных явлений, то в случае малопревращенного алевролитового сланца протекание подобных процессов менее вероятно.

Наряду с ведущей ролью высших парафинов в алкановой фракции, отличительной особенностью полученных смол является также очень низкое содержание олефинов и повышенная концентрация изопреноидных углеводородов $\left(i \mathrm{C}_{18}-i \mathrm{C}_{20}\right)$.

Кислотное обогащение вызывает существенное облегчение состава алканов смолы: после обогащения их состав приближается к обычному для алканов сланцевых смол (рис. 5). В смоле полукоксования обогащенного алевролитового сланца в области $\mathrm{C}_{13}-\mathrm{C}_{17}$ наблюдается явное преобладание не только $\boldsymbol{\mu}$-алканов с нечетным, но и $\boldsymbol{\mu}$-1-алкенов с четным числом атомов углерода в цепи над соседними гомологами, что характерно для продуктов термической деструкции керогенов; присутствуют $\mu$-алкены с двойной связью, расположенной в средней части цепи, - раньше они были обнаружены в смолах полукоксования кукерсита (ордовик) и припятского сланца (девон).

Таким образом, ОВ исследовавшихся сланцев, хотя и отличается некоторым своеобразием, но, если судить по составу битумоида, гидролизуемой части и смолы полукоксования, по химическим особенностям 
исходного биологического материала, оно имеет много общего с ОВ более поздних отложений. Это подтверждается данными о том, что при переходе от докембрия к посткембрию не было резких изменений в характере процессов осадконакопления [ $\left.{ }^{20}\right]$.

Авторы благодарят И. Клесмента за ценные замечания и просмотр работы.

\section{ЛИТЕРАТУРА}

1. Сиддоренко С. А., Сидоренко А. В. Органическое вещество в осадочнометаморфических породах докембрия. М., 1975.

2. Аалоэ А. О., Марк Э. Ю., Мянниль Р. М., Мююрисепп К. К., О р в и к у К. К. Обзор стратиграфии палеозойских и четвертичных отложений Эстонской ССР. Таллин, 1958.

3. Руководство по анализу битумов и рассеянного органического вещества горных пород. Л., 11966.

4. K lesment, I. Application of chromatographic methods in biogeochemical investigations. - J. Chromatogr., 1974, v. 91, N 2, p. 705-713.

5. Robinson, W. E. Isolation procedures for kerogens and associated soluble organic materials. - In: Organic geochemistry. Methods and results. Berlin, Heidelberg, New York, 1969, p. 181-195.

6. Н е р у ч е в С. Г. Нефтепроизводящие свиты и миграция нефти. Л., 1962.

7. Н е р у ч е в С. Г. Нефтепронзводящие свиты и миграция нефти. Л., 1969.

8. Г е ол о г и я СССР. Т. 17. Иркутская область. М., 1962.

9. Mathews, R. T., Cook, A. C., Johns, R. B. Relation between $n$-alkane distribution and effective coalification temperatures in some Permian shales. Geochim. Cosmochim. Acta, 1975, v. 39, N 9, p. 1237-1243.

10. Johnson, R. W., Calder, J. A. Early diagenesis of fatty acids and hydrocarbons in a salt marsh environment. - Geochim. Cosmochim. Acta, 1973, v. 37, N 8, p. 1943-1955.

11. Allan, J., Murchis on, D., S c ott, E., W a t s on, S. Organic geochemistry of thermally metamorphosed fossil wood. - Fuel, 1975, v. 54, N 4, p. 283-287.

12. Ши шенина В. П., Попова Н. В., Чернова Т. Г., Телкова М. С., Морозов а Р. М. К геохимии углеводородов органического вещества современных осадков. - Геохимия, 1974, № 8, с. 1212-1219.

13. У ров К. Э., Л и ст рем А. И. Сравнительная характеристика органического вещества девонского и юрского горючих сланцев Ухтинского месторождения. Химия тв. топлива, 1977 , № 2 , с. $71-77$.

14. Matsuda, H., Koy a ma, T. Positional isomer composition of monounsaturated fatty acids from a lacustrine sediment. - Geochim. Cosmochim. Acta, 1977, v. $41, \mathrm{~N} 2$, p. $341-345$.

15. B a d e r, R. G., Hoop, D. W., S mith, J. B. Recovery of dissolved organic matter in sea-water and organic sorption by particulate material. - Geochim. Cosmochim. Acta, 1960 , v. 19 , N 4, p. $236-243$.

16. Развозжаева Э. А., Петров Б. В., Тюкавкина Н. А. Сложные эфиры карбоновых кислот в метаморфических породах Патомского нагорья. - Геохимия, 1973 , № 5 , с. $790-796$.

17. Дробот Д. И. Органическое вещество докембрийских и нижнекембрийских отложений Юга Сибирской платформы и его роль в процессах нефте- и газообразования. - В кн.: Тезисы 5-го Всесоюзного семинара «Органическое вещество в современных и ископаемых осадках». М., 1976, с. $179 \multimap 180$.

18. Dung worth, G., Schwartz, A. W. Kerogen isolates from the Precambrian of South Africa and Australia: Analysis for carbonized micro-organisms and pyrolysis gas liquid chromatography. - In: Advances in organic geochemistry. Oxford, New York, 1972, p. 699-706.

19. Shimo yama, A, Johns, W. D. Formation of alkanes from fatty acids in the presence of $\mathrm{CaCO}_{3}$. - Geochim. Cosmochim. Acta, 1972, v. 36, N 1, p. 87-91.

20. С и до ре н ко А. В. О едином историко-геологическом принципе изучения докембрия и посткембрия. - Докл. АН СССР, 1969, т. 186, № 1, с. 166-169.

\section{Ннститут химии \\ Академии наук Эстонской ССР}

Поступила в редакцию 6/III 1978 
K. UROV, Ada LISTROM, A. JAANUS

\section{EESTI NSV JA IRKUTSKI OBLASTI EELKAMBRIUMI KILTKIVIDE ORGAANILISE AINE VORDLEV ISELOOMUSTUS}

Artiklis on esitatud kotlini (Eesti NSV) ja homolhiini lademe (Irkutski oblast) eelkambriumi $\left(\mathrm{Pt}_{3}\right)$ kiltkivi orgaanilise aine lahustuvas osas sisalduvate $n$-alkaanide, isoprenoidsete süsivesinike, $n$-alkanoonide-2 ning küllastunud rasvhapete jaotuskõverad ahelapikkuse järgi, samuti andmieid kivimite utteproduktide ja hüdrolüsaatide koostise kohta.

\section{K. UROV, Ada LISTROM, A. JAANUS}

\section{A COMPARATIVE STUDY ON THE ORGANIC MATTER OF PRE-CAMBRIAN SHALES OF ESTONIA AND IRKUTSK REGION}

The organic matter of two Pre-Cambrian $\left(\mathrm{Pt}_{3}\right)$ shales from Kotlin Stage (Estonian SSR) and Homolkhin Stage (Irkutsk Region) has been investigated. The distribution of $n$-alkanes, isoprenoid alkanes, $n$-alkanones-2 and saturated fatty acids of the bitumens according to the chain length as well as data concerning the composition of semicoking products and hydrolyzable part of kerogens are given. 